\title{
BEHAVIORAL CHANGES OF LABORATORY ANIMALS INTOXICATED WITH CHEMICAL WEAPONS
}

\author{
N. Bozakova ${ }^{1}$, V. Ivanov $^{2 *}$ \\ ${ }^{1}$ Department of General Animal Breeding, Animal Hygiene, Ethology and Animal Protection Section. \\ Faculty of Veterinary Medicine, Trakia University, Stara Zagora, Bulgaria \\ ${ }^{2}$ Department of Neurology, Psychiatry and MDS, Faculty of Medicine, Trakia University, \\ Stara Zagora, Bulgaria
}

\begin{abstract}
Chemical weapons have been used repeatedly in the history of humanity for wars and terrorist acts. They have caused major insults on human health and taken many lives. The most frequent tests for the effects of chemical weapons involve various laboratory animals that are known to experience behavioral changes and disorders.

The purpose of this overview is to examine the most frequent changes and disorders in the behavior of laboratory animals - mice, rats, guinea pigs, cats, and various primates intoxicated with chemical weapons.
\end{abstract}

Key words: Behavioural changes and disorders, laboratory animals, intoxications, chemical warfare agents.

\section{INTRODUCTION}

There is evidence that animals can serve as indicators of chemical weapons attack. Various sources in medical literature provide proof that wild or domestic animals exposed to certain chemical weapons are more sensitive, with a shorter latency period or increased risk of exposure compared to humans. Similar documented communications have been searched for in the past. Limited data for studying the behavior of domestic or wild animals could involve airborne chemical agents as well as an increased risk of environmental exposure. At present, there is enough data for the routine use of certain animals due to their sensitivity to chemical weapons. There must be good communication among professionals working with different chemical weapons monitoring systems, including the results of animal behavior observations. Veterinarians are therefore also obliged to participate (1).

\footnotetext{
*Correspondence to: Veselin Ivanov, 11 Armeyska Str, 6000 Stara Zagora, Bulgaria, Department of Neurology, Psychiatry and MDS, Faculty of Medicine, Trakia University, Phone: +35942664326, E-mail:veskoasenov@abv.bg
}

This report focuses on neuropathic poisonous substances used for military purposes. They are the most current, and the most dangerous chemical weapons. They are potent inhibitors of the enzyme acetylcholine esterase. This enzyme participates in the transmission of nerve impulses between the neurons, including the central nervous system. For this reason, a number of animal behavioral changes have been observed in intoxicated animals.

The most important agents of the neuropathic fighting poisonous substances are tabun, sarin, cyclosarin, soman and Vx.

The aim of this report is to reflect on the main behavioural changes and some structural changes in the brain in various types of experimental animals under the influence of major neuropathic poisonous substances tabun, sarin, cyclosarin, soman and Vx.

\section{Exposition}

The major changes in the of animal behavior poisoned by neuropathic poisonous substances for military purposes include deviations in motor activity in an open field test, altered pressure on the lever in the Skinner box, disturbed labyrinth orientation, response errors 
in a test that requires choosing. This could be related to the pathogenic effects of the aforementioned fighting poisonous substances on the brain structures - hippocampus, amygdala and thalamus in experimental animals.

Changes in animal movement activity. Animals exposed to chemical weapons exhibit changes in their motor activity. Kassa et al., (2001) investigated the effect of sarin on the behavior of rats. The results show that 3 months after inhalation exposure, sarine in symptomatic and asymptomatic doses may cause decreased activity and mobility, change in gait, increase in stereotyped behavior in rats. The same authors found signs of increased excitability in rats at exposure to sarin after 6 or 12 months. These behavioral changes included an increase in activity, body temperature, and the force of trapping the lower back of rats after 6 months of exposure to this asymptomatic poisonous substance and after 12 months with symptomatic doses (2). Reduced locomotor activity in mice was found in sarin exposure, three times in low dosages (3). Other authors - Nieminen et al., (1990) and Haggerty et al., (1986) have experimented and found that soman in low (4) and high (5) doses also reduces the motor activity of intoxicated rats in an open field test. Blick et al., (1994) observed in rhinotoxin infected Macaque rhesus monkeys, a balance disorder found by balancing a Latin square (6). Southern American cockroaches Blaptika dubia also alter their motor activity after tabun, sarin, cyclosarin, soman and Vx intoxication, as well as when intoxicated with the sulfur mustard and lewisite blister agents (7).

Behavior changes in Skinner box. In Skinner box animals learned to push a lever before chemical weapons intoxication, receiving food as a reward. Genovese et al., (2009) found that the ability of rats to push the lever is not impaired in single exposure at low sarin concentrations. This ability, however, changes in repeated low-dose exposures $\left(4 \mathrm{mg} / \mathrm{m}^{3}\right.$ over 60 minutes) with no apparent signs of intoxication (except for myosis) (8). Minor effects on rat behavior were observed in similar experiments with low $\mathrm{Vx}$ concentrations (9). Subcutaneous injection of soman at a dose of 80 micrograms / $\mathrm{kg}$ suppresses this ability (10).

Behavioural changes in labyrinth. Animals were trained to reach food in a labyrinth. Genovese et al., (2009) found that rat orientation in mazes was poorly influenced by single-dose low-dose sarine intakes. In multiple exposures, however, with low doses (4mg / m 3 for 60 minutes), rats made more mistakes and their orientation required more time. The deficiency dropped 3 weeks after the last intoxication (8). Sarin in high single doses severely disturbed the orientation of rats (11). Orientation functions improved when $5 \mathrm{mg}$ of midazolam (anticonvulsant drug) was administered at $5 \mathrm{mg} / \mathrm{kg}$ (12) 5 minutes after intoxication. Low-dose Vx-treated patients responded poorly (9). Tabun significantly affected the orientation of rats in a labyrinth (13).

Changes in Acoustic Flicker Response. Haggerty et al., (1986) reported that decreased amplitude of rat response and increase of latency period in acoustic shock were observed two hours after soman intoxication in rats (5).

Changes in choice when choosing a choice between two different options. In this test, ordinary marmosets were trained to perform tasks - to make choices between two different options. Muggleton et al. (2003) found that sarin or soman intoxication caused mistakes in marmoset response. Prior to intoxication, some of the animals were treated with scopolamine or physostigmine, and another with a combination of scopalamine and physostigmine. Separately, scopolamine and physostigmine did not induce behavioral mitigation, but in combination they reduced it (14).

Histological changes in the brain of laboratory animals after intoxication. Grauer et al., (2008) investigated the toxic effect of sarin vapors in the brain on rats. Free-moving rats were exposed to sarin vapors $(34.2 \pm 0.8$ micrograms / liter) for 10 minutes. Histological analysis revealed typical cell loss 1 week after inhalation exposure. Neuronal inflammation was demonstrated by a 20 -fold increase in prostaglandin PGE2 levels 24 hours after exposure, which significantly decreased 6 days later. In addition, a delayed increase in PGE2 was observed for 1 month and continued to increase up to 6 months after sarin exposure. Glial activation following neuronal damage was demonstrated by an increased level of peripheral benzodiazepine receptors (PBR) seen in the brain 4 and 6 months after exposure. At the same time muscarinic receptors did not respond (11). Collombet et al., (2006) identified the toxic effect of soman on mouse brains. Neuronal damage from the poisonous substance in the hippocampus and amygdala was assessed by measuring the density of the omega 3 receptors and the hemalon-phloxin staining (15). Britt et al., 
(2000) investigated the soman impact on monkeys - Rhesus Macaques. Thirty-six of these species were treated with soman and 10 days later were euthanized. The brain, the heart and the skeletal muscles were studied histologically. Brain lesions were observed in 9 out of 15 animals which showed convulsions and only 1 out of 21 had no convulsions. Brain lesions were limited to hippocampus, amygdala, and thalamus (per animal). These included neuronal necrosis and dropping, spongiosis, gliosis, astrocytosis and vascularization. Heart lesions included myocardial degeneration and necrosis. Three animals had brain and heart injuries, 7 had only brain lesions, and 3 had heart lesions alone. Skeletal muscle lesions, though minimal to mild, have been described in most animals. They have experienced muscle tremor (16). Proliferation of glial cells in layer 4 and in the deep sections of rat cortex layer 3 were observed with repeated administration of soman (17).

Changes in the levels of other mediators. Soman not only increased acetylcholine levels by inhibiting cholinesterases but it changed the levels of some other neurotransmitters, including norepinephrine, dopamine and serotonin (rabbit tests) (18).

\section{CONCLUSION}

Chemical weapons change the behavior of a number of laboratory animals, sometimes even without other signs of intoxication. These reactions should be studied and eventually used in practice by humans. Treating toxic substances with toxin-lowering drugs also reduces behavioral changes caused by nervous paralytic chemical weapons.

\section{ACKNOWLEDGEMENTS}

This article has been supported by scientific projects №7/2016 of Medical faculty, Trakia University.

\section{REFERENCES}

1. Rabinowitz P., Wiley J, Odofin L, Wilcox $\mathrm{M}$, DeinFJ.Animals as sentinels of chemical terrorism agents: an evidence based review. Clin Toxicol (Phila). 46(2):93-100, 2008.

2. Kassa J, Koupilová M, Herink J, Vachek J. The long-term influence of low-level sarin exposure on behavioral and neurophysiological functions in rats. Acta Medica (Hradec Kralove). 44(1):21-7, 2001.

3. Mach M, Grubbs RD, Price WA, Nagaoka M, Dubovický M, Lucot JB. Delayed behavioral and endocrine effects of sarin
BOZAKOVA N, et al. and stress exposure in mice. $J$ Appl Toxicol. 28(2):132-9, 2008.

4. Nieminen SA, Lecklin A, Heikkinen O, Ylitalo P. Acute behavioural effects of the organophosphates sarin and soman in rats. Pharmacol Toxicol. 67(1):36-40, 1990.

5. Haggerty GC, Kurtz PJ, Armstrong RD. Duration and intensity of behavioral change after sublethal exposure to soman in rats. Neurobehav Toxicol Teratol. 8(6):695-702, 1986.

6. Blick DW, Murphy MR, Brown GC, Yochmowitz MG, Fanton JW, Hartgraves SL. Acute behavioral toxicity of pyridostigmine or soman in primates. Toxicol Appl Pharmacol. 126(2):311-8, 1994.

7. Worek F, Seeger T, Neumaier K, Wille T, Thiermann H. Blaptica dubia as sentinels for exposure to chemical warfare agents - a pilot study. Toxicol Lett. 262:12-16. 2016.

8. Genovese RF, Mioduszewski RJ, Benton BJ, Pare MA, Cooksey JA. Behavioral evaluation of rats following low-level inhalation exposure to sarin. Pharmacol Biochem Behav. 91(4):517-25, 2009.

9. Genovese $\mathrm{RF}^{1}$, Benton BJ, Lee EH, Shippee SJ, Jakubowski EM. Behavioral and biochemical evaluation of sub-lethal inhalation exposure to VX in rats. Toxicology. 232(1-2):109-18, 2007.

10.Brezenoff HE, McGee J, Hymowitz N. Inhibition of acetylcholinesterase in the gut inhibits schedule-controlled behavior in the rat. Life Sci. 37(1):49-54, 1985.

11.Grauer E, Chapman S, Rabinovitz I, Raveh L, Weissman BA, Kadar T, Allon N. Single whole-body exposure to sarin vapor in rats: long-term neuronal and behavioral deficits. Toxicol Appl Pharmacol. 227(2):265-74, 2008.

12. Gilat E, Kadar T, Levy A, Rabinovitz I, Cohen G, Kapon Y, Sahar R, Brandeis R. Anticonvulsant treatment of sarin-induced seizures with nasal midazolam: an electrographic, behavioral, and histological study in freely moving rats. Toxicol Appl Pharmacol. 209(1):74-85, 2005.

13.Kunesová G, Kassa J. Comparison of effects of different antidotes on tabuninduced cognitive impairment in rats using water maze. Acta Medica (Hradec Kralove). 49(2):113-8, 2006.

14.Muggleton NG, Bowditch AP, Crofts HS, Scott EA, Pearce PC. Assessment of a combination of physostigmine and scopolamine as pretreatment against the behavioural effects of organophosphates in the common marmoset (Callithrix jacchus). 
Psychopharmacology (Berl). 166(3):21220, 2003.

15. Collombet JM, Baubichon D, Masqueliez C, Bernabé D, Four E, Burckhart MF, Lallement G. Effects of aspirin and mefenamic acid on soman poisoninginduced neuropathology in mice. Drug Chem Toxicol. 29(2):167-81, 2006.

16. Britt JO Jr${ }^{1}$, Martin JL, Okerberg CV, Dick EJ Jr. Histopathologic changes in the brain, heart, and skeletal muscle of rhesus macaques, ten days after exposure to soman
BOZAKOVA N, et al. (an organophosphorus nerve agent). Comp Med. 50(2):133-9, 2000.

17. Hymowitz N, Ploshnick A, Laemle L, Brezenoff $H$. Effects of repeated administration of soman on schedulecontrolled behavior and brain in the rat. Neurotoxicol Teratol. 12(1):47-56, 1990.

18. Hsu CH, Hu CY, Robinson CP. The effects of soman in vitro on catechol-Omethyltransferase and monoamine oxidase activities in rabbit tissues. $J$ Biochem Toxicol. 5(3):183-5, 1990. 